\title{
Erratum to: Clinical findings on ANCA-associated renal vasculitis from the Japan RPGN registry obtained via a questionnaire survey
}

\author{
Kunihiro Yamagata $\cdot$ Joichi Usui $\cdot$ Hitoshi Sugiyama • \\ Kosaku Nitta $\cdot$ Takashi Wada $\cdot$ Eri Muso $\cdot$ Yoshihiro Arimura • \\ Akio Koyama $\cdot$ Hirofumi Makino $\cdot$ Seiichi Matsuo
}

Published online: 23 March 2013

(C) Japanese Society of Nephrology 2013

\section{Erratum to: Clin Exp Nephrol \\ DOI 10.1007/s10157-012-0740-1}

Table 2 and Fig. 2 appeared incorrectly in the article cited above. They are correctly shown as follows.
Table 2 The clinical grading system for predicting RPGN patient prognosis [1]

\begin{tabular}{lllll}
\hline Clinical score & $\begin{array}{l}\text { Serum } \\
\text { creatinine } \\
(\mathrm{mg} / \mathrm{dl})\end{array}$ & $\begin{array}{l}\text { Age } \\
\text { (years old) }\end{array}$ & $\begin{array}{l}\text { Lung } \\
\text { involvement }\end{array}$ & $\begin{array}{l}\text { Serum CRP } \\
(\mathrm{mg} / \mathrm{dl})\end{array}$ \\
\hline 0 & $<3$ & $\leq 59$ & Negative & $<2.6$ \\
1 & $3-6$ & $60-69$ & & $2.6-10.0$ \\
2 & $\geq 6$ & $\geq 70$ & Positive & $>10.0$ \\
3 & Dialysis & & & \\
\hline Clinical grade & & & & \\
\hline I & & & & $0-2$ \\
II & & & $3-5$ \\
III & & & $6-7$ \\
IV & & & $8-9$ \\
\hline
\end{tabular}

The online version of the original article can be found under doi:10.1007/s10157-012-0740-1.

K. Yamagata $(\bowtie) \cdot$ J. Usui

Department of Nephrology, Faculty of Medicine, University of Tsukuba, 1-1-1 Tennodai, Tsukuba, Ibaraki 305-8575, Japan e-mail: kidney@md.tsukuba.ac.jp

J. Usui

e-mail: j-usui@md.tsukuba.ac.jp

H. Sugiyama $\cdot$ H. Makino

Department of Medicine and Clinical Science, Okayama University Graduate School of Medicine, Dentistry, and Pharmaceutical Sciences, Okayama, Japan

K. Nitta

Department of Medicine, Kidney Center, Tokyo Women's Medical University, Tokyo, Japan

T. Wada

Division of Nephrology, Kanazawa University Hospital,

Kanazawa, Japan

\section{E. Muso}

Department of Nephrology and Dialysis, The Tazuke Kofukai Medical Research Institute, Kitano Hospital, Osaka, Japan

Y. Arimura

First Department of Internal Medicine, Kyorin University School of Medicine, Tokyo, Japan

\footnotetext{
A. Koyama

Department of Nephrology, Tsukuba Memorial Hospital, Tsukuba, Ibaraki, Japan

\section{S. Matsuo}

Department of Nephrology, Internal Medicine, Nagoya

University Graduate School of Medicine, Nagoya, Japan
} 
Fig. 2 Treatment algorithm for ANCA-associated RPGN in Japan [2]. ESRD end-stage renal disease, OCS oral corticosteroid, $M P$ methylprednisolone, $P S L$ prednisolone, CYC cyclophosphamide, IVCYC intravenous cyclophosphamide

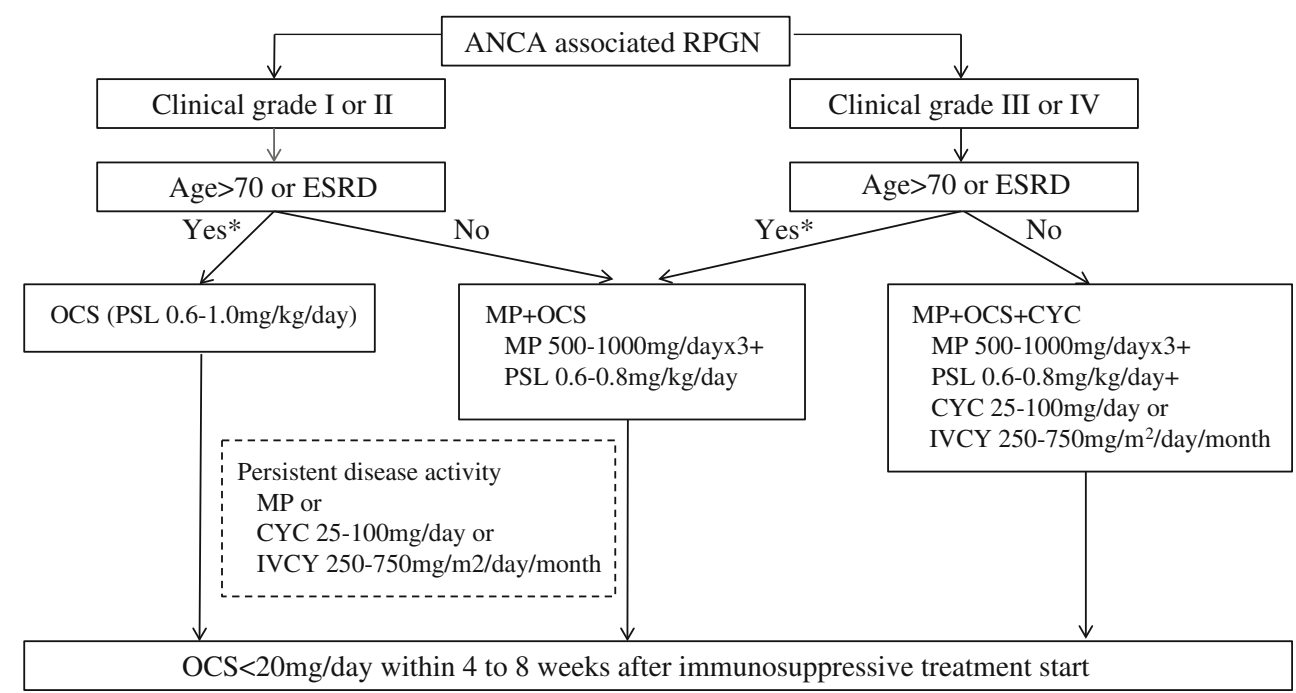

*Older patients often suffered from opportunistic infection. Milder treatment (less dose of PSL, without MP or CYC) were recommended. 